\title{
Cryptococcal Antigen Testing in an Integrated Medical System: Eastern Wisconsin
}

Marianne Klumph

Brian Hoeynck

Dennis J. Baumgardner

Follow this and additional works at: https://aah.org/jpcrr

Part of the Bacterial Infections and Mycoses Commons, Community Health and Preventive Medicine Commons, Diagnosis Commons, Environmental Public Health Commons, Infectious Disease Commons, Medical Microbiology Commons, Primary Care Commons, and the Pulmonology Commons

\section{Recommended Citation}

Klumph M, Hoeynck B, Baumgardner DJ. Cryptococcal antigen testing in an integrated medical system: eastern Wisconsin. J Patient Cent Res Rev. 2020;7:57-62. doi: 10.17294/2330-0698.1717

Published quarterly by Midwest-based health system Advocate Aurora Health and indexed in PubMed Central, the Journal of Patient-Centered Research and Reviews (JPCRR) is an open access, peer-reviewed medical journal focused on disseminating scholarly works devoted to improving patient-centered care practices, health outcomes, and the patient experience. 


\title{
Cryptococcal Antigen Testing in an Integrated Medical System: Eastern Wisconsin
}

\author{
Marianne Klumph, MA, ${ }^{1,2}$ Brian Hoeynck, BS, ${ }^{3}$ Dennis J. Baumgardner, MD ${ }^{1,2,4}$ \\ ${ }^{1}$ Department of Family Medicine, Aurora UW Medical Group, Aurora Health Care, Milwaukee, WI; ${ }^{2}$ Center for Urban \\ Population Health, Milwaukee, WI; ${ }^{3}$ Aurora Research Institute, Aurora Health Care, Milwaukee, WI; ${ }^{4}$ Department of \\ Family Medicine and Community Health, University of Wisconsin School of Medicine and Public Health, Madison, WI
}

\begin{abstract}
Cryptococcosis is a serious environmentally acquired endemic fungal infection commonly associated with immunocompromised hosts. Little is known regarding frequency or distribution in Wisconsin. We explored the geodemographic and clinical features of patients tested with cryptococcal antigen tests (CrAg) — previously shown to be $>90 \%$ sensitive and $>90 \%$ specific — within a large health care system located in eastern Wisconsin. To examine this, we retrospectively analyzed 1465 CrAg tests on 1211 unique patients (female: 50.2\%; white race: $73.9 \%$; mean age: $53.7 \pm 16.5$ years). At least one CrAg result was positive in 23 of 1211 patients (1.9\%). From these, 21 of 23 were immunocompromised. Positive patients were disproportionately male $(82.6 \%)$ and nonwhite $(3.8 \%$ of those tested vs $1.2 \%$ of whites tested); $\mathrm{P}<0.01$ for both. These associations remained in multivariable models. Positive patients were not significantly older (59.1 vs 53.6 years; $P=0.07$ ). Overall, 17 separate zip codes had at least one positive case. Positive patients were more prevalent in the zip codes that included the city of Milwaukee (11 of 377 [2.9\% of those tested] vs 12 of 834 [1.4\% of all those tested in the remaining area of the state]), but this difference was not statistically significant. No other case clustering or close proximity to waterways was observed $(41 \%$ were $<162 \mathrm{~m}$ from green space, similar to historical controls). Overall, male sex, nonwhite race/ethnicity, and immunocompromised status, not zip code, were statistically associated with positive CrAg. (J Patient Cent Res Rev. 2020;7:57-62.)
\end{abstract}

Keywords $\quad$ cryptococcosis; Cryptococcus; mycoses; antigens, fungal; AIDS-related opportunistic infections

$\mathrm{C}$ ryptococcosis is a potentially serious endemic fungal infection. ${ }^{1}$ The two major human-pathogenic species (often distinct geographically) are Cryptococcus neoformans and Cryptococcus gattii. Risk factors for disease include exposure to an environmental source of the organism. Environmental associations of these fungal species include certain trees and soils, potentially influenced by certain climatic or anthropic factors (and bird guano for C. neoformans). ${ }^{1-7}$ Cryptococcus-related environments may include common human-frequented sites of potential exposure like urban parks. ${ }^{7}$ Except for the recently proposed association with the oral cavity, ${ }^{8,9}$ these

Correspondence: Dennis J. Baumgardner, MD, Aurora Sinai Medical Center, 1020 N. 12th Street, \#4180, Milwaukee, WI 53233 (dennis.baumgardner@aurora.org) organisms are not part of the human microflora, but they may cause asymptomatic infection or colonization. ${ }^{1}$

Cryptococcus fungus enters the body through inhalation. ${ }^{1}$ The potential for infection increases markedly for people affected by acquired immune deficiency syndrome (AIDS) or in various immunocompromised states resulting from cancers and their treatments, corticosteroid therapy, and pediatric innate immune defects. ${ }^{1,10}$ Similarly, incidence rates appear to be proportional to the percentage of individuals in a population with inadequately treated AIDS or other immunocompromising conditions. ${ }^{1}$ In fact, epidemiologic data from the World Health Organization suggest that nearly 8000 cases of opportunistic cryptococcal meningitis infection occur each year among HIV-infected individual in North America, resulting in an average of 700 annual deaths. ${ }^{11}$ 
Cryptococcal infection is often readily demonstrated by microscopic examination, culture, or cryptococcal antigen detection test (CrAg). The latter not only allows for simple, rapid, and low-cost testing for the diagnosis but is reportedly more than $90 \%$ sensitive and $90 \%$ specific for disease. ${ }^{1}$ In some cases, a CrAg of blood or cerebrospinal fluid will be positive before the fungus is demonstrated in culture. ${ }^{1,12}$ Unfortunately, the $\mathrm{CrAg}$ cannot distinguish between the two humanpathogenic Cryptococcus species. ${ }^{13}$ This may become important regionally, given the 4 identified isolates of C. gatti in the Midwest. ${ }^{14}$

To our knowledge, nothing has been reported in the literature regarding the frequency or distribution of cryptococcosis in Wisconsin since the 1960s. ${ }^{15}$ The aims of this study were to explore the geodemographic features of eastern Wisconsin patients for whom $\mathrm{CrAg}$ was performed and examine the clinical features of those who tested positive for cryptococcal infection.

\section{METHODS}

A retrospective review of electronic medical record (EMR) data from the affiliated laboratory of a large, integrated health system spanning eastern Wisconsin and northeastern Illinois, which houses medical records of more than 1.2 million unique patients, was conducted. This area contains the majority of Wisconsin's urban and suburban population. Subjects were all inpatients and outpatients who had $\mathrm{CrAg}$ from January 2013 to April 2017.

The laboratory used the latex agglutination-modeled Remel $^{\mathrm{TM}}$ Cryptococcus Antigen Test Kits (Thermo Scientific, Lenexa, KS) for the detection of antigen. Patients with 1 or more positive $\mathrm{CrAg}$ were always considered positive, and patient demographic features (Table 1) were used from the first identified positive test. For patients with multiple negative CrAg results, data were taken from the first test. In addition, for comparison of individuals with any positive $\mathrm{CrAg}$ to those with negative $\mathrm{CrAg}$, a manual EMR review of all CrAg-positive patients and the first $700 \mathrm{CrAg}$ negative patients, alphabetically, was performed. This comparison examined immunocompromising conditions listed in the EMR and type of clinical presentation prior to obtaining $\mathrm{CrAg}$.

Fisher exact test or t-test was used for univariable comparisons between patients with at least one

Table 1. Demographic Features of Subjects by Cryptococcal Antigen Test (CrAg) Result

\begin{tabular}{|c|c|c|c|c|}
\hline Characteristic & $\begin{array}{c}\text { Positive CrAg } \\
n=23\end{array}$ & $\begin{array}{c}\text { Negative CrAg } \\
n=1188\end{array}$ & $\begin{array}{c}\text { Total } \\
\mathrm{N}=1211^{\mathrm{a}}\end{array}$ & $P$ \\
\hline Mean age, years \pm SD & $59.1 \pm 13.5$ & $53.6 \pm 16.6$ & $53.7 \pm 16.5$ & 0.066 \\
\hline \multicolumn{5}{|l|}{ Sex, n (\%) } \\
\hline Female & $4(0.7 \%)$ & 603 (99.3\%) & 607 (50.2\%) & \\
\hline Male & $19(3.2 \%)$ & $584(96.8 \%)$ & $603(49.8 \%)$ & $0.007^{b}$ \\
\hline \multicolumn{5}{|l|}{ Race/Ethnicity, n (\%) } \\
\hline White & $11(1.2 \%)$ & $883(98.8 \%)$ & $894(73.9 \%)$ & \\
\hline Black & $7(4.5 \%)$ & $149(95.5 \%)$ & $156(12.9 \%)$ & $0.011^{\circ}$ \\
\hline Hispanic & $3(2.8 \%)$ & $103(97.2 \%)$ & 106 (8.8\%) & $0.178^{\circ}$ \\
\hline Asian & $2(5.9 \%)$ & 32 (94.1\%) & $34(2.8 \%)$ & $0.079^{\circ}$ \\
\hline Native American & $0(0.0 \%)$ & $6(100.0 \%)$ & $6(0.5 \%)$ & $1.000^{\circ}$ \\
\hline Unknown & $0(0.0 \%)$ & $14(100.0 \%)$ & $14(1.2 \%)$ & $1.000^{\circ}$ \\
\hline All nonwhite & $12(3.8 \%)$ & 304 (96.2\%) & $316(26.1 \%)$ & $0.002^{c}$ \\
\hline
\end{tabular}

${ }^{a}$ Due to missing data, total number for sex and race/ethnicity categories was 1210 .

${ }^{b}$ Compared to CrAg-positive females (Fisher exact test).

${ }^{\circ}$ Compared to CrAg-positive whites (Fisher exact test). 
positive $\mathrm{CrAg}$ test and those who only tested negative. Stepwise and binary logistic regression were used for multivariable analysis.

Approval for this study was obtained from the local institutional review board. Note that this study is not a population-based survey, nor an analysis of cliniciandiagnosed cryptococcosis, but rather a dissection of patients with clinician-ordered $\mathrm{CrAg}$ in one health system.

\section{RESULTS}

A total of 1465 unique CrAg tests (741 on serum, 723 on cerebrospinal fluid, 1 other specimen), including multiple tests on the same patient, were performed on 1211 unique patients during the study period. The CrAg-tested study population was $50.2 \%$ female, $73.9 \%$ white, and had a mean age of 53.7 years (standard deviation: 16.5 years) (Table 1 ).

At least one $\mathrm{CrAg}$ was positive in 23 of 1211 $(1.9 \%)$ patients. Of these 23 individuals, 21 were immunocompromised (6 transplant patients, 5 with HIV, 4 with malignancy, 3 had chronic corticosteroid use, 2 with diabetes mellitus, and 1 with combined immunodeficiency). Further detailed analysis of all positive patients plus the first 700 negative patients $(n=723)$ revealed that $58.2 \%$ had an immunocompromising condition listed. Of those patients with an immunocompromised condition, 53.5\% had only a central nervous system (CNS) presentation, $23.2 \%$ had only a pulmonary presentation, $7.9 \%$ had both presentations, and $15.4 \%$ had neither presentation. Based on $58.2 \%$ having immunocompromising condition, 13 of 23 immunocompromised patients would have been predicted to test positive; in reality, $21 \operatorname{did}(\mathrm{P}<0.001)$.

Overall, $7 \mathrm{CrAg}$-positive patients were diagnosed with cryptococcal meningitis, and 2 additional patients had cerebrospinal fluid that tested CrAg-positive. Six patients were diagnosed with disseminated cryptococcosis; 3 patients had a pulmonary presentation (but no diagnosis); 1 patient had a combined pulmonary and CNS presentation but died before precise diagnosis could be established; and 4 patients had $\mathrm{CrAg}$-positive serum but no recorded cryptococcosis diagnosis.

Of the 18 CrAg-positive patients with a recorded fungal culture, 17 were positive for $C$. neoformans or
C. gattii (our microbiology laboratory did not routinely differentiate the species at the time of this study). Of the 2 patients without apparent immunodeficiency, 1 had confirmed disseminated cryptococcosis. The other patient had an otherwise unexplained pneumonia; however, fungal culture was not done, and a Cryptococcus serum antibody titer was low (1:2).

CrAg-positive patients were disproportionately male (19 of 23 [3.2\% of all males tested] vs 4 of 23 female [0.7\% of all females tested]; $\mathrm{P}=0.002$ ) and nonwhite (12 of 23 [3.8\% of all nonwhite patients tested] vs 11 of 23 white [1.2\% of all white patients tested]; $\mathrm{P}=0.007)$. These associations remained significant in a multivariable binary regression model (Table 2). In the 723-patient subcohort that included all 23 positive cases and 700 negative cases, detailed immune status data in the EMR was available for 678 patients. A stepwise regression model based on this population revealed that male sex, nonwhite race, and immunocompromised state remained significantly associated with positive CrAg result $(\mathrm{P}<0.02$ for all $)$.

Table 2. Multivariable Binary Regression Model of Demographics Associated With Positive Cryptococcal Antigen Test $(n=1210)$

\begin{tabular}{lccc}
\hline Characteristic & Odds Ratio & $\mathbf{9 5 \%} \mathbf{C l}$ & $\boldsymbol{P}$ \\
\hline Male gender & 5.00 & $1.67-14.29$ & 0.007 \\
Nonwhite & 3.18 & $1.38-7.31$ & 0.002 \\
\hline
\end{tabular}

The geographic distribution of patients with positive $\mathrm{CrAg}$ in the eastern Wisconsin catchment area is illustrated in Figure 1. Overall, 17 separate zip codes had 1 positive case; 2 city of Milwaukee zip codes had 3 each, the closest two living 193 meters apart. No other CrAg-positive case clustering or close proximity to waterways was observed; $41 \%$ were less than 162 $\mathrm{m}$ (ie, $<0.1$ miles) from green space (parks/farms/ forests). Positive patients were more prevalent in the $532 \times x$ zip codes that include Milwaukee (11 of 377 [2.9\% of those tested] vs 12 of 834 [ $1.4 \%$ of all those tested in the remaining catchment area of the state]), but this difference was not significant $(\mathrm{P}=0.176)$.

Further examining the 678 Wisconsin patients with detailed immune status data in the EMR, 144 of 233 

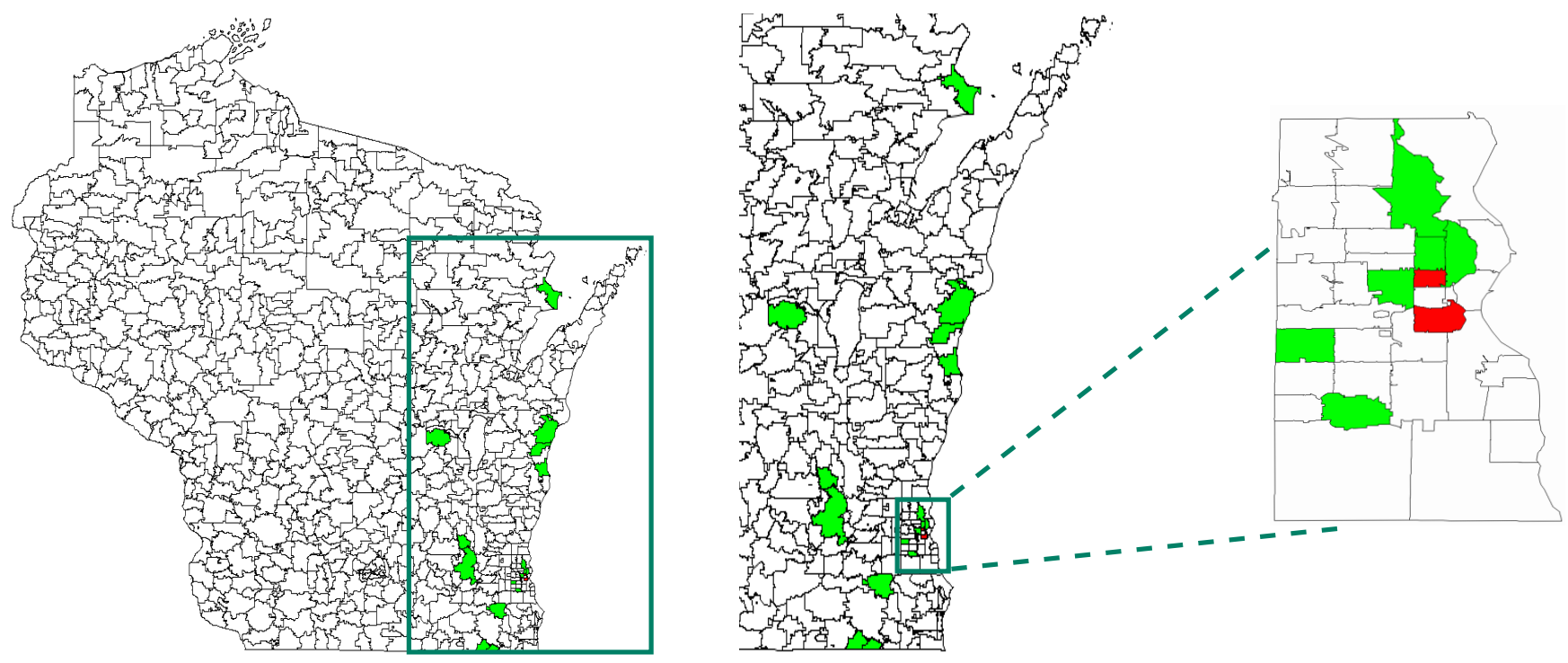

Figure 1. Map of zip code location of individuals with positive cryptococcal antigen tests. Panels show, from left to right, state of Wisconsin, eastern Wisconsin catchment area, and magnified view of Milwaukee County. Overall, 17 separate zip codes contained 1 positive case (shaded in green); 2 city of Milwaukee zip codes had 3 each (shaded in red).

in Milwaukee zip codes $(61.8 \%)$ were noted to be immunocompromised compared to 251 of 445 in the rest of Wisconsin zip codes $(56.4 \%$; $\mathrm{P}=0.190)$. Similarly, examining the 17 zip codes with 1 or more CrAg-positive cases (all in Wisconsin, none in northeastern Illinois), tested individuals were more likely to be immunocompromised compared with those from zip codes without a positive case (88 of 133 [66.2\%] vs 307 of 545 [56.3\%], P=0.040). Indeed, 18 of 25 total CrAg-tested individuals residing in the pair of Milwaukee zip codes that each had $3 \mathrm{CrAg}$-positive cases were noted to be immunocompromised.

\section{DISCUSSION}

The incidence of cryptococcosis is not well known in the United States, as it is not a reportable disease in many states. ${ }^{16}$ Limited data suggest an overall incidence of $0.4-1.3$ cases/100,000 annually, and a $2.9 \%$ prevalence of cryptococcal antigen in serum of patients with HIV and low CD4 counts. ${ }^{16}$ Thus, it seems that our CrAg-positive rate (1.9\%) is consistent with national statistics given a tested population with half or more having an immunocompromising condition and with cryptococcosis in the differential diagnosis. A hospital discharge-based survey of 18 states, including Wisconsin, indicated a 1997-2009 cryptococcal meningitis hospitalization rate of $<2$ per 1 million population for HIV-infected individuals and 2-4 per 1 million rate for those without HIV. ${ }^{17}$ Extrapolating our data and considering 1.2 million patients in our health system at the time of the study, we would estimate 3 per 1 million persons have CNSbased Cryptococcus infections indicated by $\mathrm{CrAg}$, per year, a figure consistent with those reported numbers.

Serum CrAg may be falsely negative in patients with pulmonary cryptococcosis unless the disease has disseminated. ${ }^{18}$ Thus, the 3 patients who had only a pulmonary presentation in our study may underestimate this manifestation in our population. Pulmonary cryptococcosis may spread to the CNS, worsening the prognosis of an already serious disease but increasing the likelihood of detection. ${ }^{18}$

The preponderance of male patients with positive $\mathrm{CrAg}$ is consistent with previous literature. ${ }^{1}$ This elevated male cryptococcosis prevalence predates the HIV outbreak and may be due to gender differences in macrophage response to Cryptococcus. ${ }^{19}$ A sample of the wide variety of reported immunocompromising conditions predisposing to cryptococcosis was seen in our study. ${ }^{1,17,18}$ 
The proportion of CrAg-positive patients in our study who were within $162 \mathrm{~m}(<0.1$ miles $)$ from green space (41\%) was similar to a historical control group of 250 randomly selected adult patients with communityacquired pneumonia taken from this same catchment area (39.6\%) for a 2006-2013 blastomycosis study. ${ }^{20}$ Our data suggest that Wisconsin zip codes having 1 or more patients with positive $\mathrm{CrAg}$ contained a higher proportion of individuals considered to be immunocompromised and that the higher proportion of individuals with positive $\mathrm{CrAg}$ in and near Milwaukee reflect this fact. Taken together, perhaps this suggests that the proportion of persons in a given eastern Wisconsin locale who are immunocompromised has more influence on the incidence of cryptococcal infections than does any geographic feature. Further research is required to test this hypothesis.

Interestingly, recent molecular studies indicate that Cryptococcus species may be members of the human oral microbiota in some individuals. ${ }^{8,9}$ It has been suggested that oral carriage could lead to opportunistic cryptococcal infections. ${ }^{8}$ We are currently undertaking a culture-based study to determine if pathogenic Cryptococcus species indeed reside within the human oral cavity. If this proves to be the case, the path to cryptococcal infection in some persons could be a two-step process, first from the environmental source to oral colonization, then spreading to other organ systems.

The limitations of this descriptive study are those inherent to a retrospective EMR review in a single health system. Therefore, statistical comparisons must be interpreted with caution pending further research. We included performance of $\mathrm{CrAg}$ as the sole entry criteria for the study and did not base the comparison of positive and negative cases on additional confirmation such as culture.

In addition, CrAg does not distinguish between $C$. neoformans and $C$. gattii. This distinction may be clinically important, as there was some evidence that the latter may lead to more pulmonary and CNS morbidity than the former and may require longer treatment. ${ }^{21} C$. gattii appears to commonly infect normal hosts; however, it is recognized as also causing serious disease in HIV- infected persons. ${ }^{22}$ In addition to the known endemicity of $C$. gattii in Washington and Oregon, this species is now being recognized in other regions of the United States, including the southeast, ${ }^{22}$ where it may have been present for several thousand years. ${ }^{23} C$. gattii is likely present in the environment just south of southeastern Wisconsin, meaning it may be endemic to the catchment area of our study. ${ }^{14}$ Initial attempts to culture $C$. gattii from natural environments in Wisconsin have been unsuccessful. ${ }^{24}$ There is need for routine testing to differentiate between both Cryptococcus species and to increase clinician awareness of the nuances regarding $C$. neoformans and C. gattii. 22

\section{Patient-Friendly Recap}

- Cryptococcosis is a fungal infection acquired through inhalation from the environment. It can cause meningitis, pneumonia, or widespread damage to cells and body tissue, usually in people with weakened immune systems.

- The authors identified cases of cryptococcal infection contracted by people living in eastern Wisconsin and studied the characteristics of these individuals and features of their respective zip codes.

- They found that among patients testing positive for cryptococcosis, male sex, nonwhite race/ethnicity, and a weakened immune system - but not geographic features such as proximity to water - were associated with having a positive test.

\section{Author Contributions}

Study design: Baumgardner. Data acquisition or analysis: all authors. Manuscript drafting: Klumph, Baumgardner. Critical revision: Klumph, Baumgardner.

\section{Acknowledgments}

Special thanks to Julie Prabucki, MT, of ACL Laboratories (West Allis, WI) for providing laboratory data and inspiration, Kayla Heslin, MPH, of Aurora Health Care for the creation of the Wisconsin map to represent zip codes with positive Cryptococcus cases, and to Jessica Kram, MPH, of Aurora Health Care for providing valuable feedback throughout the project.

\section{Conflicts of Interest}

None. 


\section{References}

1. Perfect JR. Cryptococcosis (Cryptococcus neoformans and Cryptococcus gattii). In: Bennett JE, Dolin R, Blaser MJ (eds). Mandell, Douglas, and Bennett's Principles and Practice of Infectious Diseases, Eighth Edition. Philadelphia, PA: Elsevier Saunders, 2015, pp. 2934-48.

2. Bartlett KH, Cheng PY, Duncan C, et al. A decade of experience: Cryptococcus gattii in British Columbia. Mycopathologia. 2012;173:311-9. CrossRef

3. Uejio CK, Mak S, Manangan A, Luber G, Bartlett KH. Climatic influences on Cryptococcus gattii populations, Vancouver Island, Canada, 2002-2004. Emerg Infect Dis. 2015;21:1989-96. CrossRef

4. Kidd SE, Bach PJ, Hingston AO, et al. Cryptococcus gattii dispersal mechanisms, British Columbia, Canada. Emerg Infect Dis. 2007;13:51-7.

5. Springer DJ, Billmyre RB, Filler EE, et al. Cryptococcus gattii VGIII isolates causing infections in HIV/AIDS patients in Southern California: identification of the local environmental source as arboreal. PLoS Pathog. 2014:10:e1004285. CrossRef

6. Kidd SE, Chow Y, Mak S, et al. Characterization of environmental sources of the human and animal pathogen Cryptococcus gattii in British Columbia, Canada, and the Pacific Northwest of the United States. Appl Environ Microbiol. 2007;73:1433-43. CrossRef

7. Mortenson JA, Bartlett KH, Wilson RW, Lockhart SR. Detection of Cryptococcus gattii in selected urban parks of the Willamette Valley, Oregon. Mycopathologia. 2013;175:351-5. CrossRef

8. Ghannoum MA, Jurevic RJ, Mukherjee PK, et al. Characterization of the oral fungal microbiome (mycobiome) in healthy individuals. PLoS Pathog. 2010;6(1): e1000713. CrossRef

9. Dupuy AK, David MS, Li L, et al. Redefining the human oral mycobiome with improved practices in amplicon-based taxonomy: discovery of Malassezia as a prominent commensal. PLoS One. 2014;9(3):e90899. CrossRef

10. Kontoyiannis DP, Peitsch WK, Reddy BT, et al. Cryptococcosis in patients with cancer. Clin Infect Dis. 2001;32(11):e145-50. CrossRef

11. Park BJ, Wannemuehler KA, Marston BJ, Govender N, Pappas PG, Chiller TM. Estimation of the current global burden of cryptococcal meningitis among persons living with HIV/ AIDS. AIDS. 2009;23:525-30. $\underline{\text { CrossRef }}$

12. Kaplan JE, Vallabhaneni S, Smith RM, Chideya-Chihota S, Chehab J, Park B. Cryptococcal antigen screening and early antifungal treatment to prevent cryptococcal meningitis: a review of the literature. J Acquir Immune Defic Syndr. 2015;68 Suppl 3:S331-9. $\underline{\text { CrossRef }}$
13. Iverson SA, Chiller T, Beekmann S, Polgreen PM, Harris J. Recognition and diagnosis of Cryptococcus gattii infections in the United States. Emerg Infect Dis. 2012;18:1012-4. CrossRef

14. Moritz D, Mena Lora AJ, Blumer B, Harrington AT. Recovery of Cryptococcus gattii from an infected ventriculo-peritoneal shunt, Illinois, USA. Emerg Infect Dis. 2018;24:1382-3. CrossRef

15. McDonough ES, Lewis AL, Penn LA. Relationship of Cryptococcus neoformans to pigeons in Milwaukee, Wisconsin. Public Health Rep. 1966;81:1119-23. CrossRef

16. Centers for Disease Control and Prevention. C. neoformans infection statistics. Last reviewed 2018 Oct 9. https://www. cdc.gov/fungal/diseases/cryptococcosis-neoformans/statistics. html. Accessed March 26, 2019.

17. Pyrgos V, Seitz AE, Steiner CA, Prevots DR, Williamson PR. Epidemiology of cryptococcal meningitis in the US: 19972009. PLoS One. 2013;8(2):e56269. rossRef

18. Setianingrum F, Rautemaa-Richardson R, Denning DW. Pulmonary cryptococcosis: a review of pathobiology and clinical aspects. Med Mycol. 2019;57:133-50. CrossRef

19. McClelland EE, Hobbs LM, Rivera J, et al. The role of host gender in the pathogenesis of Cryptococcus neoformans infections. PLoS One. 2013;8(5):e63632. CrossRef

20. Huber ME, Baumgardner DJ, Kram JJ, Lemke MA. Geodemographic features of human blastomycosis in eastern Wisconsin. J Patient Cent Res Rev. 2016;3:90-8. CrossRef

21. Chaturvedi S, Chaturvedi V. Virulence mechanisms of Cryptococcus gattii: convergence and divergence. In: Heitman J, Kozel TR, Kwon-Chung KJ, Perfect JR, Casadevall A. Cryptococcus: From Human Pathogen to Model Yeast. Washington, DC: ASM Press, 2011, pp. 189-201.

22. Bruner KT, Franco-Paredes C, Henao-Martínez AF, Steele GM, Chastain DB. Cryptococcus gattii complex infections in HIV-infected patients, Southeastern United States. Emerg Infect Dis. 2018;24:1998-2002. CrossRef

23. Lockhart SR, Roe CC, Engelthaler DM. Timing the origin of Cryptococcus gattii sensu stricto, Southeastern United States. Emerg Infect Dis. 2018;24:2095-7. CrossRef

24. Ward SL, Hoeynck B, Baumgardner DJ. Isolation of Cryptococcus-like yeast from natural environments. (abstr.) J Patient Cent Res Rev. 2018;5:320. $\underline{\text { CrossRef }}$

(C) 2020 Aurora Health Care, Inc. 